\title{
Effects of caudal autotomy on the locomotor performance of Micrablepharus atticolus (Squamata, Gymnophthalmidae)
}

\author{
Naiane Arantes Silva', Gabriel Henrique O. Caetano², Pedro Henrique Campelo³, Vitor Hugo Gomes Lacerda Cav- \\ alcante $^{4}$, Leandro Braga Godinho', Donald Bailey Miles ${ }^{5}$, Henrique Monteiro Paulino ${ }^{3}$, Júlio Miguel Alvarenga da \\ Silva ${ }^{1}$, Bruno Araújo de Souza ${ }^{1}$, Hosmano Batista Ferreira Silva ${ }^{1}$ and Guarino Rinaldi Colli ${ }^{3}$ \\ 1 Universidade do Estado de Mato Grosso, Campus Nova Xavantina, Avenida Expedição Roncador Xingu, \\ Nova Xavantina, MT 78690, Brazil \\ 2 Jacob Blaustein Center for Scientific Cooperation, The Jacob Blaustein Institutes for Desert Research, Ben- \\ Gurion University of the Negev, Midreshet Ben-Gurion 849900, Israel. \\ 3 Universidade de Brasília, Campus Universitário Darcy Ribeiro, Asa Norte, Brasília, DF 70910, Brazil \\ 4 Instituto Federal do Piauí, 64000-040, Teresina, Piauí, Brasil. \\ 5 Department of Biology, Ohio University, Athens, OH, 45701, USA
}

\begin{abstract}
Caudal autotomy is a dramatic adaptation used by many lizard species to evade predators. Most studies to date indicate that caudal autotomy impairs lizard locomotor performance. Surprisingly, some species bearing the longest tails show negligible impacts of caudal autotomy on sprint speed. Part of this variation has been attributed to lineage effects. For the first time, we model the effects of caudal autotomy on the locomotor performance of a gymnophthalmid lizard, Micrablepharus atticolus, characterized by a long and bright blue tail. To improve model accuracy, we incorporated the effects of several covariates. We found that body temperature, pregnancy, mass, collection site, and the length of the regenerated portion of the tail were the most important predictors of locomotor performance in Micrablepharus atticolus. However, sprint speed was unaffected by tail loss. Apparently, the long tail of M. atticolus is more useful when using undulation amidst the leaf litter and not when using quadrupedal locomotion on a flat surface. Our findings highlight the intricate relationships among physiological, morphological, and behavioral traits. We suggest that future studies about the impacts of caudal autotomy among long-tailed lizards should consider the role of different microhabitats/substrates on locomotor performance, using laboratory conditions that closely mimic their natural environments.
\end{abstract}

Keywords: lizard; autotomy; tail; locomotion; performance; temperature; predation

\section{Introduction}

Throughout evolutionary time, an "arms race" fostered varied strategies of prey capture and predator escape [1]. Autotomy - the self-amputation of a body part in response to an attack by a predator-is one of the most dramatic adaptations to avoid predation [2]. Caudal autotomy among reptiles has an ancient origin and was present in captorhinids from the Early Permian [3]. It persists to this day among squamate reptiles, in some species of snakes and most lizards, allowing prey to escape while the predator is distracted by the abandoned tail part [4-7]. The detachment of the tail in most species occurs through pre-established, intravertebral fracture planes, the oldest and most common form of autotomy to date, allowing a new tail to grow supported by a calcified cartilage tube [8-11].

Despite the immediate benefit of avoiding predation, autotomy also involves energy costs that can influence survival. For instance, even when resources are limiting, tail regeneration is a priority, probably associated with long-term survival and reproductive 
success $[12,13]$. Thus, the production of a new tail can negatively affect the energy balance, immunity, growth rate, social status, and immediate reproductive success [2,14]. Besides, autotomy results in the temporary loss of an important mechanism to avoid predation. Therefore, autotomized individuals may alter their patterns of activity and space use, as well as foraging schedules and frequencies, to minimize exposure to predators $[15,16]$.

In addition to affecting behavior, caudal autotomy affects the locomotor performance of some species. The tail acts as a counterweight, balancing the head and body during racing; therefore, its absence results in weight transfer to the forelimbs, making it challenging to move [4]. Moreover, the tail can act as an inertial damper of pelvic girdle movements, and its loss causes disordered oscillation of the hind limbs during the race [5] and reduced jump stability and performance [17]. In general, caudal autotomy leads to decreased locomotor performance [18]. However, it may not interfere $[19,20]$ or even increase locomotor performance [21]. These opposite results may relate to interspecific differences in predation intensity throughout ontogeny, life habits, and sexual dimorphism [15]. For example, in sexually dimorphic species where males have conspicuous coloration, their locomotor performance is little affected by autotomy, as potential predators and competitors can easily see them [18]. Still, variation exists between and within evolutionary lineages associated with different tail shapes and functions, such as sexual displays, predator distraction, defense, balance, fat storage, stabilization, and an auxiliary organ in climbing [20,22].

The lizard Micrablepharus atticolus Rodrigues, 1996 (Squamata, Gymnophthalmidae) is endemic and widely distributed in the South American Cerrado [23,24]. Individuals of this species are diurnal, semifossorial, and live among the leaf litter of grasslands and savannas [25-28]. Reproductive activity peaks in the dry season, and populations undergo an almost complete annual replacement [29]. The two recognized species of Micrablepharus have an elongate trunk and tail, short limbs, and digit reduction on the forelimbs (complete loss of digit I), whereas the hindlimbs follow the pentadactyl condition [30,31]. They exhibit intermittent quadrupedal locomotion, combining conspicuous axial traveling waves with trot-like coordination of the limbs [32-34]. The vertebral axis is the main effector of locomotion, while the limbs play an auxiliary role. On low friction substrates, the axial system of locomotion predominates, but the limbs become increasingly involved as substrate friction increases and with increasing speed [33]. Micrablepharus atticolus has a long and bright blue tail that, in open environments, contributes to divert attention from visually oriented predators to a non-vital part of the body at the time of an attack, which may be associated with higher rates of autotomy in more open environments [35].

Tail loss in Micrablepharus atticolus does not affect the body condition, suggesting that the energetic costs of autotomy are low or that individuals compensate for the tail loss by increasing the foraging rate [35]. Consequently, autotomy may not impair locomotor performance by reducing energy reserves [36]. However, because of the importance of the axial system during locomotion [33], tail loss may compromise sprint speed. Locomotor performance is an essential determinant of fitness because its reduction can undermine survival, reproductive success [37,38], foraging [39,40], and social dominance [41]. Since environmental variation affects autotomy rates in M. atticolus but these do not affect survival [35], studying the effect of autotomy on the locomotor performance of lizards inhabiting different environments can contribute to the understanding of possible compensatory mechanisms.

Here, we investigate the effects of caudal autotomy on the locomotor performance of Micrablepharus atticolus from two different environments, one in the central Cerrado and another in the Cerrado-Amazonia transition. We take into account the effects of geography, sex, body temperature, and ontogeny since (1) locomotor performance tends to be lower in females, especially during pregnancy, by the effect of the additional burden represented by the litter [42,43]; (2) there is a positive allometric relationship between body size and locomotor performance [44]; and (3) central Cerrado lizards are expected to have better locomotor performance, assuming that environmental conditions should be 
optimal for performance in the central part of species distributions [45]. Moreover, we investigate whether the effects of autotomy on locomotor performance are proportional to the size of the remaining or regenerated portion of the tail [46].

\section{Materials and Methods}

Study sites

We collected data from lizards captured at two sites: Reserva do IBGE $\left(15^{\circ} 56^{\prime} 06^{\prime \prime} \mathrm{S}\right.$, $\left.47^{\circ} 52^{\prime} 09^{\prime \prime} \mathrm{W}\right)$, a protected area in Brasília, Distrito Federal, Brazil, in the central area of

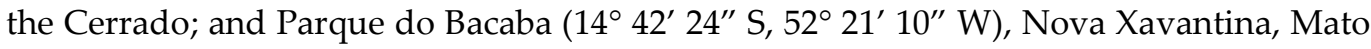
Grosso, Brazil, in the Cerrado-Amazon transition. The climate in both sites is tropical with dry winter, Aw in Köppen's classification [47], with a dry season from May to September and a rainy season from October to April. In Brasília, the average annual accumulated precipitation is $1,477.4 \mathrm{~mm}$, and the average annual temperature is $21.0^{\circ} \mathrm{C}$; in Nova Xavantina, $1,417.7 \mathrm{~mm}$ and $24.8^{\circ} \mathrm{C}$, respectively (https://portal.inmet.gov.br/normais).

\section{Lizard sampling}

We captured lizards using arrays of pitfall traps interconnected by drift fences. Each array consisted of four plastic buckets of $35 \mathrm{~L}$, buried to ground level and arranged in the form of a " $Y$ " with one in the center and three at the tips, interconnected by three 6-m long and $50-\mathrm{cm}$ high galvanized steel plates that functioned as guide fences. We only used adult individuals in the analyses, comprising 39 lizards from Brasília and 64 from Nova Xavantina.

Immediately after capture, we took the following measurements from each lizard: body mass, using a Pesola spring dynamometer (0.1 g precision); snout-vent length (SVL), total tail length, and length of the non-autotomized part of the tail-in lizards with caudal autotomy - with a metal ruler ( $1 \mathrm{~mm}$ precision); and sex, whenever possible, through palpation of the abdomen for the presence of vitellogenic follicles or eggs in pregnant females and the extrusion of the hemipenis in males. Next, we transported lizards to the lab and housed them in individual terraria, with vermiculite substrate and water ad libitum. In a period of up to 24 hours after capture, we carried out the ecophysiology experiments (below), after which we permanently marked (by toe-clipping) and released lizards next to their exact capture sites.

\section{Locomotor performance}

We recorded sprint speed on a wooden track $(300 \mathrm{~cm}$ long $\times 30 \mathrm{~cm}$ high $\times 40 \mathrm{~cm}$ wide). We induced each lizard to run as fast as possible by manual stimulation, mimicking a predatory chase, to record the maximum speed. Due to the thermal sensitivity of sprint speed [48], we conducted runs at three different temperatures - cold, ambient, and hotwith a $5^{\circ} \mathrm{C}$ difference between them in each experiment. We used gel ice packs and incandescent lamps to alter the lizards' body temperature, monitored with a fast-reading cloacal thermometer (L-K Industries Miller \& Weber T-6000 Cloacal 0/50 ${ }^{\circ} \mathrm{C} 0.2$ precision). We conducted two trials of each lizard at each temperature, totaling six runs. We recorded runs at $420 \mathrm{fps}$ with a Casio HS EX-FH25 digital camera mounted on an aluminum tripod at $1.5 \mathrm{~m}$ height in the center of the track. Later, we analyzed videos with Tracker 4.80 to obtain the maximum sprint speed of each lizard at each temperature.

Within at least one hour after the last run, we measured the critical thermal minimum and maximum, with a one-hour interval between them, using a fast-reading cloacal thermometer (L-K Industries Miller \& Weber T-6000 Cloacal 0/50 ${ }^{\circ} \mathrm{C} 0.2$ precision). We exposed lizards to the sources of heat and cold mentioned above until they lost the righting response, i.e., when they could not return to the prone position after turned in a supine position without leading the animal to death. To build performance curves (below), we considered that sprint speed is equal to zero at the critical thermal minimum and 
maximum. The Animal Use Ethics Committee of the University of Brasília approved all procedures (process 33786/2016).

\section{Statistical analyses}

To determine the effect of caudal autotomy on locomotor performance, we built generalized mixed additive models - GAMMs [49] with the MGCV package [50] in the R environment [51]. We used GAMMs to generate performance curves and evaluate the influence of predictors on the shape and location of curves because they allow nonlinear responses and are flexible due to the nonparametric smoothing functions used in sections of the data [52]. In these models, we used the maximum sprint speed as the response variable; the individual as a random factor; and sex, pregnancy (gravid/non-gravid), body temperature, mass, SVL, relative tail length (total tail length / SVL), caudal autotomy (autotomized/not autotomized), relative length of the regenerated portion of the tail (length of the regenerated portion of tail / SVL), and study site (Brasília/Nova Xavantina) as fixed factors. To assess model significance, we used a likelihood-ratio test comparing its fit with that of a null model, composed only of the response variable, the intersection, and the random factor.

To evaluate predictor importance, we used a combination of model selection and averaging based on the Akaike Information Criterion adjusted for small samples (AIC $C_{c}$, with package MUMIN [53]. Model selection attempts to improve our understanding of the relationship between the response and the predictors by reducing the model's dimension. However, this approach often results in biased regression parameters and too small respective standard errors in finite samples because they do not reflect the uncertainty related to the model selection process [54,55]. On the other hand, model averaging incorporates the uncertainty intrinsic to model selection by combining parameter estimates across different models [56,57]. Using this approach, we examined the complete set of possible models combining the fixed effects to obtain model-averaged standardized parameter estimates for statistical inference [58,59]. We used averages calculated across all models ("full averages"), assuming that each model includes all variables but that in some models the corresponding coefficient (and its respective variance) is set to zero, which avoids biasing the values away from zero [60]. Moreover, we calculated the importance of each predictor as the sum of Akaike weights across all models containing that predictor. The Akaike weight is the normalized model likelihood, divided by the sum of these values across all $k$ models [56]:

$$
w A I C_{k}=\frac{\exp \left(-\frac{1}{2} \Delta A I C_{k}\right)}{\sum_{k=1}^{k} \exp \left(-\frac{1}{2} \Delta A I C_{k}\right)}
$$

\section{Results}

We obtained ecophysiological data from 39 lizards from Brasília and 64 lizards from Nova Xavantina (Table 1). The likelihood-ratio test indicated that our full GAMM differed significantly from a null model and adequately fitted the data $\left(\chi^{2}[1]=219.129, P \sim 0\right.$, adjusted- $r^{2}=0.622$ ). Among the parametric terms in the model, collection site and pregnancy were significant, while among smooth terms, body temperature, body mass, and the length of the regenerated portion of the tail were significant (Table 2). Model selection and averaging indicated that body temperature, pregnancy, mass, collection site, and the length of the regenerated portion of the tail, in this order, were the most important predictors of locomotor performance in Micrablepharus atticolus (Table 3). The GAMM predicted maximum locomotor performance around $31^{\circ} \mathrm{C}$ (Fig. 1A). Gravid females had lower performance than males and non-gravid females (Fig. 1B), and lizards from Nova Xavantina achieved higher performance-and at higher temperatures - than lizards from 
Brasília (Fig. 1C). Finally, the locomotor performance increased with body mass (Fig. 1D) and the relative length of the regenerated portion of the tail (Fig. 1E).

Table 1. Summary statistics of ecophysiological parameters of Micrablepharus atticolus from Brasília and Nova Xavantina, Brazil. Values represent the mean \pm one standard deviation.

\begin{tabular}{cccc}
\hline Parameter & Brasília & Nova Xavantina & Total \\
\hline Sample size & 39 & 64 & 103 \\
Mass (g) & $1.49 \pm 0.35$ & $0.82 \pm 0.19$ & $1.06 \pm 0.41$ \\
Snout-vent length (mm) & $38.22 \pm 3.06$ & $34.98 \pm 2.76$ & $36.12 \pm 3.26$ \\
Tail length (mm) & $48.62 \pm 13.74$ & $46.37 \pm 17.64$ & $47.17 \pm 16.39$ \\
Relative tail length & $1.27 \pm 0.34$ & $1.32 \pm 0.50$ & $1.31 \pm 0.45$ \\
Length of regenerated portion of tail (mm) & $6.38 \pm 10.30$ & $9.99 \pm 11.95$ & $8.71 \pm 11.51$ \\
Relative length of regenerated portion of tail & $0.16 \pm 0.26$ & $0.28 \pm 0.34$ & $0.24 \pm 0.32$ \\
Body temperature during runs ( $\left.{ }^{\circ} \mathrm{C}\right)$ & $27.94 \pm 6.72$ & $27.53 \pm 5.43$ & $27.67 \pm 5.88$ \\
Critical thermal minimum $\left({ }^{\circ} \mathrm{C}\right)$ & $13.90 \pm 1.78$ & $15.20 \pm 3.29$ & $14.70 \pm 2.08$ \\
Critical thermal maximum $\left({ }^{\circ} \mathrm{C}\right)$ & $44.41 \pm 1.84$ & $40.00 \pm 3.09$ & $41.69 \pm 3.43$ \\
Sprint speed (maximum) & $0.07 \pm 0.02$ & $0.10 \pm 0.04$ & $0.09 \pm 0.04$ \\
\hline
\end{tabular}

Table 2. Full generalized additive mixed model (GAMM) relating various predictors to the locomotor performance (sprint speed) of the lizard Micrablepharus atticolus in Brazil. AU: caudal autotomy (yes/no), CCr: total tail length, RCr: length of the regenerated portion of the tail, SVL: snout-vent length, NX: Nova Xavantina, edf: expected degrees-of-freedom.

\begin{tabular}{|c|c|c|c|c|}
\hline \multicolumn{5}{|c|}{ Parametric Terms } \\
\hline Term & Estimate & Std. Error & $t$ & $P$ \\
\hline (Intercept) & 0.0411 & 0.0065 & 6.3080 & $6.62 \mathrm{e}-10$ \\
\hline LocalNX & 0.0220 & 0.0069 & 3.1920 & 0.0015 \\
\hline SexMale & 0.0015 & 0.0045 & 0.3230 & 0.7467 \\
\hline AUYes & 0.0000 & 0.0070 & -0.0040 & 0.9970 \\
\hline Pregnancy & -0.0203 & 0.0068 & -2.9700 & 0.0031 \\
\hline \multicolumn{5}{|c|}{ Smooth Terms } \\
\hline Term & edf & Ref. df & $F$ & $P$ \\
\hline s(Temperature) & 7.976 & 7.976 & 95.569 & $<2 \mathrm{e}-16$ \\
\hline $\mathrm{s}(\mathrm{CCr})$ & 1.000 & 1.000 & 0.036 & 0.84979 \\
\hline $\mathrm{s}(\mathrm{RCr})$ & 1.000 & 1.000 & 3.037 & 0.08203 \\
\hline$s(S V L)$ & 1.000 & 1.000 & 0.365 & 0.54589 \\
\hline s(Mass) & 3.119 & 3.119 & 4.983 & 0.00259 \\
\hline
\end{tabular}

Table 3. Model selection and averaging of generalized additive mixed models (GAMMs) relating various predictors to the locomotor performance (sprint speed) of the lizard Micrablepharus atticolus in Brazil. AU: caudal autotomy (yes/no), RT: length of regenerated portion of tail, AICc: Akaike information criterion corrected for small samples, $\triangle A I C_{c}$ : difference between given and best model, wAICc: Akaike weight.

\begin{tabular}{cccccc}
\hline & & & \\
\hline & Model Selection & & & \\
\hline & df & logLik & AIC $_{c}$ & $\Delta_{\text {AIC }}$ & wAIC $_{c}$ \\
\hline Pregnancy + Site + s(Mass) + s(RCr) + s(Temperature) & 11 & 934.81 & -1847.06 & 0.00 & 0.25 \\
AU + Pregnancy + Site + s(Mass) + s(RCr) + s(Temperature) & 12 & 934.84 & -1845.01 & 2.05 & 0.09 \\
Pregnancy + Site + s(Mass) + s(RCr) + s(Temperature)+ Sex & 12 & 934.82 & -1844.97 & 2.10 & 0.09 \\
Pregnancy + Site + s(Mass) + s(Temperature) & 9 & 931.35 & -1844.32 & 2.75 & 0.06 \\
AU + Pregnancy + Site + s(Mass) + s(Temperature) & 10 & 932.22 & -1843.96 & 3.10 & 0.05 \\
Pregnancy + Site + s(Mass) + s(RCr) + s(SVL) + s(Temperature) & 13 & 934.93 & -1843.07 & 3.99 & 0.03 \\
\hline
\end{tabular}




\begin{tabular}{|c|c|c|c|c|c|c|c|c|c|}
\hline \multicolumn{10}{|c|}{ Model Averaging } \\
\hline Importance & s(Temperature) & $\begin{array}{c}\text { Pregnanc } \\
y\end{array}$ & s(Mass) & Site & $s(\mathrm{RCr})$ & AU & Sex & $\mathbf{s}(\mathrm{CCr})$ & $\mathrm{s}(\mathrm{SVL})$ \\
\hline Sum of model weights & 1.00 & 0.93 & 0.90 & 0.89 & 0.73 & 0.33 & 0.27 & 0.15 & 0.14 \\
\hline Number of containing models & 255 & 253 & 253 & 254 & 254 & 255 & 255 & 255 & 254 \\
\hline
\end{tabular}
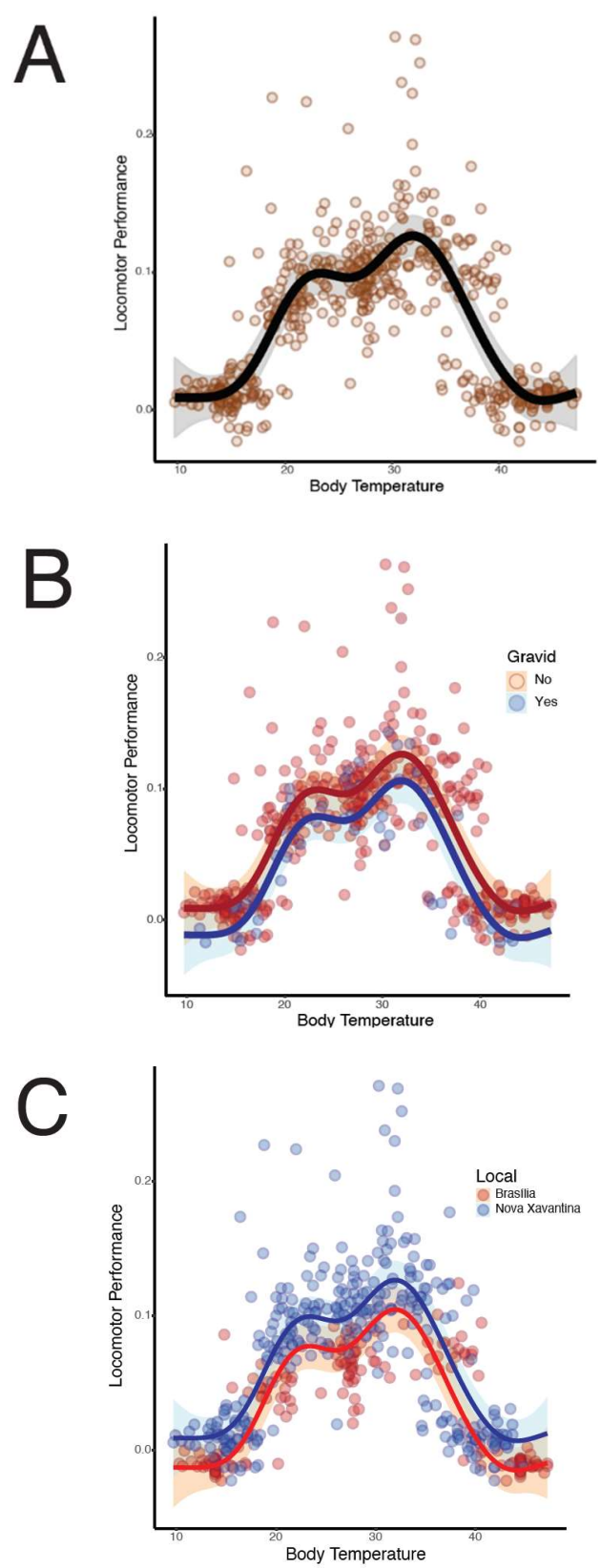

Figure 1. Locomotor performance (sprint speed) of the lizard Micrablepharus atticolus as a function of (A) body temperature, (B) body temperature and female reproductive condition (gravid females vs. non-gravid females and males), and (C) body temperature and geography. Points represent partial residuals of a generalized additive mixed model (GAMM), while the lines and bands represent the predictions and confidence limits, respectively. 

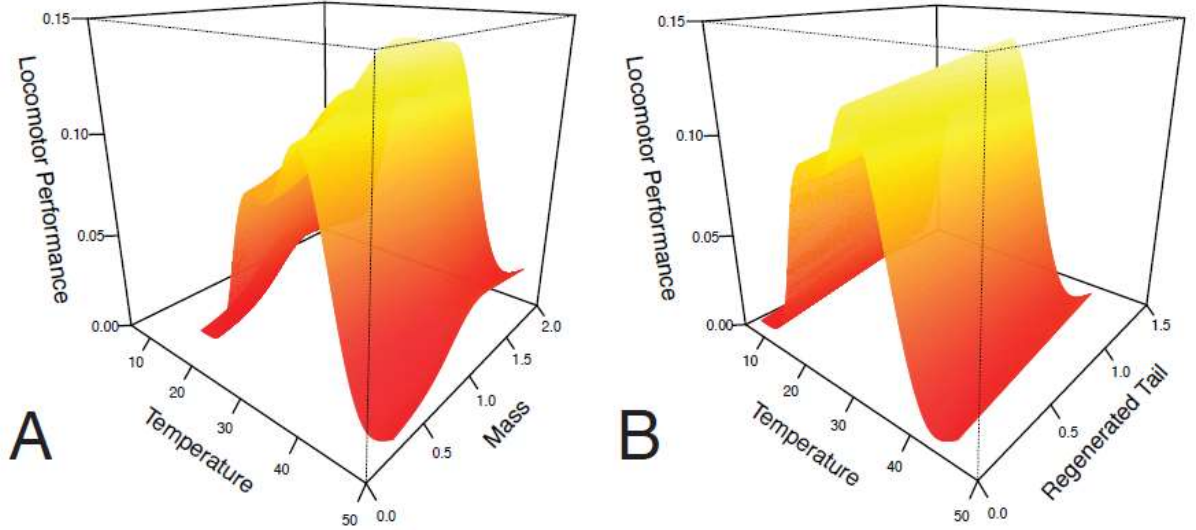

Figure 2. Locomotor performance (sprint speed) of the lizard Micrablepharus atticolus as a function of (A) body temperature and body mass, and (B) body temperature and length of the regenerated portion of the tail. The surface represents the predictions of a generalized additive mixed model (GAMM).

\section{Discussion}

We assessed the effects of caudal autotomy on the locomotor performance of Micrablepharus atticolus, controlling for the influence of several covariates. We found that the performance is significantly affected by body temperature, female reproductive condition, body mass, geography, and caudal autotomy. Overall, our findings highlight the complex patterns of coevolution among physiological, morphological, and behavioral traits and that meaningful inference and prediction based on physiological performance must consider such patterns [61-64].

Body temperature was, by far and large, the foremost factor affecting performance. This outcome is not surprising, given that body temperature is regarded as one of the most critical ecophysiological variables affecting the performance of ectotherms [65-67]. Sprint speed peaked at ca. $31^{\circ} \mathrm{C}$, which is substantially higher than that recorded for Caparaonia itaiquara $\left(24.51^{\circ} \mathrm{C}\right.$ ) and Colobodactylus dalcianus (25.81 $\left.{ }^{\circ} \mathrm{C}\right)$, two closely related gymnophthalmines from high-elevation areas in the Atlantic Forest of southeastern Brazil [68,69]. Moreover, our analyses showed that lizards from Nova Xavantina achieve higher sprint speeds at higher body temperatures than lizards from Brasília. Such differences might be related to altitudinal, latitudinal, or even phylogenetic effects [70]. As environmental temperatures in Nova Xavantina are ca. $4{ }^{\circ} \mathrm{C}$ higher than in Brasília (and even higher than in high elevations of southeastern Brazil), our results are consistent with the notion that geographic variation of thermal sensitivity in locomotor performance is adaptive, such that organisms adjust optimal performance temperatures to prevalent field body temperatures [63]. For instance, based on the principle that biochemical and physiological systems operating at high temperatures have a high catalytic capacity, the "hotter is better" hypothesis predicts a positive relationship between maximal organismal performance and optimal temperatures [71]. This relationship holds when considering interspecific [61,72] or intraspecific comparisons [73,74].

Whereas Brasília is at the core of Micrablepharus atticolus' geographic distribution, Nova Xavantina is closer to its periphery, next to the Cerrado-Amazonia ecotone [24,75]. Therefore, we expected higher physiological performance in the core population, as predicted by the core-periphery hypothesis $[45,76]$. However, we found the opposite pattern, with higher performance in the more peripheral population. Several factors might account for this result. For example, despite the centrality difference between the two sites relative to the species' range, they might have the same or even opposite patterns of environmental suitability, i.e., the geometric center of the geographic distribution may not coincide with areas of greater suitability and vice-versa [77,78]. Moreover, due to phenotypic plasticity or adaptation to local conditions, species range boundaries may not be driven by thermal performance [68,79]. 
Our analysis indicates no intersexual differences in sprint speed in Micrablepharus atticolus, most likely related to the lack of sexual size dimorphism [26]. However, we found that pregnant females have lower locomotor performance than males. This decrease likely occurs due to the additional physical load of the litter, making the body broader and heavier [80]. However, as locomotor performance increased with body mass, the lower performance in pregnant females may be related to physiological changes linked to reproduction [81], such as decreased muscle strength, reduced metabolic capacity, motivation to escape [82], and energy allocation [83]. These physiological changes ensure adequate embryonic development and remain for a while after egg-laying [81,84]. A decrease in gravid females' locomotor performance was also recorded in other lizard species [85-89]. By becoming slower, pregnant females are more susceptible to predation, and this can promote several behavioral changes during pregnancy, such as foraging near potential shelters and avoiding long races during a predatory escape.

The body mass of individuals is an essential factor in determining sprint speed [72]. We found continuously increased performance with increasing body mass, which would probably occur until the optimal mass is reached, beyond which performance decreases $[90,91]$. This increase in performance with body mass is typical among quadruped species $[41,72,92,93]$. Despite using lateral undulation when moving in the middle of the leaf litter, Micrablepharus atticolus can also rely on quadrupedal locomotion when on a flat substrate $[32,33]$. We advance that the ever-increasing locomotor performance associated with increased body mass results from the very short lifespan of M. atticolus [29], such that individuals never reach a critical body mass.

In most cases, the tail has an active role in improving lizard sprint speed, and caudal autotomy undermines locomotor performance [14,20]. Moreover, the greater the relative size of the intact tail, the higher the magnitude of sprint speed change following autotomy. However, we found that sprint speed was unaffected by tail loss but by the relative length of the regenerated portion of the tail, i.e., the longer the regenerated tail, the higher the sprint speed. Still, this effect was meager, unlike patterns documented elsewhere [42,9496]. Caudal autotomy has no impact on the locomotor performance of some lizard species $[19,20]$. Some have argued that this reflects these species' skinny and short tails [19] or even that adverse effects of autotomy result from researchers damaging the lizards' locomotor muscles during experimental tail breakage [97]. Individuals of Micrablepharus atticolus have a long tail (in our samples, $1.7 \times$ SVL in individuals with intact tails), one of the longest among gymnophthalmids [98], and we used lizards with naturally broken and regenerated tails. Therefore, these explanations cannot account for the patterns we observed.

A synthesis on the effects of tail autotomy, tail size, and locomotor performance in lizards identified clear phylogenetic patterns in the data [20]. Hence, among-lineage differences in the biomechanics of locomotion and the tail function during sprinting may account for the different effects of tail loss on locomotor performance. The single previous study on the locomotion of Micrablepharus did not address the impact of caudal autotomy on performance [33], and to the best of our knowledge, ours is the first study on this issue within Gymnophthalmidae. This lineage comprises small, cryptic, and often fossorial or semifossorial Neotropical species, characterized by many instances of the evolution of body elongation and limb reduction [30,31,99]. Indeed, fossoriality is a critical driver of the evolution of a snake-like morphology among squamates [100,101]. Therefore, in such species, the tail may have a very context-specific role in locomotion, which may not be apparent when individuals move on a flat substrate. For instance, in Colobodactylus taunayi, a gymnophthalmine, the tail remains stretched during displacement on a flat surface [98] and a similar pattern is apparent in M. maximiliani when moving on gravel or sand [Figs. 3 and 6 in 33]. Tail loss in lizards of the genus Takydromus, where the tail can be three times as long as the SVL, similarly had little effect on locomotor performance $[20,46,102]$. These species often use a three-dimensional, cluttered environment amidst the leaf litter, much like "grass-swimmer" lizards [103,104]. We conjecture that the long tail 
of M. atticolus is more useful when using undulation amidst the leaf litter and not when using quadrupedal locomotion on a flat surface. Future studies on the impacts of caudal autotomy on long-tailed lizards should consider the role of different microhabitats/substrates on locomotor performance, using laboratory conditions that closely mimic their natural environments.

Funding Information: GRC was supported by Coordenação de Aperfeiçoamento de Pessoal de Nível Superior (CAPES), Conselho Nacional de Desenvolvimento Científico e Tecnológico (CNPq), Fundação de Apoio à Pesquisa do Distrito Federal (FAPDF) and the USAID's PEER program under cooperative agreement AID-OAA-A-11-00012 for financial support. DBM was supported by NSF $(1241848,1950636)$.

AUTHOR CONTRIBUTIONS: NAS, HMP, and GRC conceived the study, conducted the analyses, and wrote the manuscript. All authors participated in fieldwork, lab work, data collection and curation, and revised the manuscript. DBM, GHOC, and GRC provided planning and supervision.

\section{Reference}

1. Dawkins, R.; Krebs, J.R. Arms races between and within species. Proc. R. Soc. Lond., B, Biol. Sci. 1979, 205, 489-511.

2. Emberts, Z.; Escalante, I.; Bateman, P.W. The ecology and evolution of autotomy. Biol. Rev. 2019, 94, 1881-1896, doi:10.1111/brv.12539.

3. LeBlanc, A.R.H.; MacDougall, M.J.; Haridy, Y.; Scott, D.; Reisz, R.R. Caudal autotomy as anti-predatory behaviour in Palaeozoic reptiles. Scientific Reports 2018, 8, 3328, doi:10.1038/s41598-018-21526-3.

4. Arnold, E.N. Caudal autotomy as a defense. In Biology of the Reptilia, Gans, C., Huey, R.B., Eds.; Ecology B: Defense and Life History: New York, 1988; Volume 16.

5. Arnold, E.N. Evolutionary aspects of tail shedding in lizards and their relatives. J Nat Hist 1984, 18, 127-169, doi:10.1080/00222938400770131.

6. Clause, A.R.; Capaldi, E.A. Caudal autotomy and regeneration in lizards. J. Exp. Zool. Part A 2006, 305, 965-973, doi:10.1002/jez.a.346.

7. Bellairs, A.d.A.; Bryant, S.V. Autotomy and regeneration in reptiles. In Biology of the Reptilia, Volume 15, Development B, Gans, C., Billet, F., Eds.; John Wiley \& Sons: New York, 1985; pp. 301-410.

8. Gilbert, E.A.; Payne, S.L.; Vickaryous, M.K. The anatomy and histology of caudal autotomy and regeneration in lizards. Physiol. Biochem. Zool. 2013, 86, 631-644, doi:10.1086/673889.

9. Ritzman, T.B.; Stroik, L.K.; Julik, E.; Hutchins, E.D.; Lasku, E.; Denardo, D.F.; Wilson-Rawls, J.; Rawls, J.A.; Kusumi, K.; Fisher, R.E. The gross anatomy of the original and regenerated tail in the green anole (Anolis carolinensis). Anat Rec 2012, 295, 1596-1608, doi:10.1002/Ar.22524.

10. Alibardi, L. Development of the axial cartilaginous skeleton in the regenerating tail of lizards. Bulletin de l'Association des Anatomistes 1995, 79, 3-9.

11. Fisher, R.E.; Geiger, L.A.; Stroik, L.K.; Hutchins, E.D.; George, R.M.; Denardo, D.F.; Kusumi, K.; Rawls, J.A.; Wilson-Rawls, J. A histological comparison of the original and regenerated tail in the green anole, Anolis carolinensis. Anat Rec 2012, 295, 1609-1619, doi:10.1002/ar.22537.

12. Maginnis, T.L. The costs of autotomy and regeneration in animals: a review and framework for future research. Behav Ecol 2006, 17, 857-872, doi:10.1093/beheco/arl010.

13. Lynn, S.E.; Borkovic, B.P.; Russell, A.P. Relative apportioning of resources to the body and regenerating tail in juvenile leopard geckos (Eublepharis macularius) maintained on different dietary rations. Physiol. Biochem. Zool. 2013, 86, 659-668, doi:10.1086/673312.

14. Bateman, P.W.; Fleming, P.A. To cut a long tail short: A review of lizard caudal autotomy studies carried out over the last 20 years. J. Zool. (Lond.) 2009, 277, 1-14, doi:10.1111/j.1469-7998.2008.00484.x.

15. Cooper Jr, W.E.; Smith, C.S. Costs and economy of autotomy for tail movement and running speed in the skink Trachylepis maculilabris. Can J Zool 2009, 87, 400-406, doi:10.1139/z09-024.

16. Cromie, G.L.; Chapple, D.G. Impact of tail loss on the behaviour and locomotor performance of two sympatric Lampropholis skink species. PLoS One 2012, 7, 34732, doi:10.1371/journal.pone.0034732.

17. Gillis, G.B.; Bonvini, L.A.; Irschick, D.J. Losing stability: tail loss and jumping in the arboreal lizard Anolis carolinensis. J Exp Biol 2009, 212, 604-609, doi:10.1242/jeb.024349.

18. Anderson, M.L.; Cavalieri, C.N.; Rodríguez-Romero, F.; Fox, S.F. The differential effect of tail autotomy on sprint performance between the sexes in the lizard Uta stansburiana. J Herpetol 2012, 46, 648-652, doi:10.1670/11-166. 
19. Huey, R.B.; Dunham, A.E.; L., O.K.; Newman, R.A. Variation in locomotor performance in demographically known populations of the lizard Sceloporus merriami. Physiol Zool 1990, 63, 845-872.

20. McElroy, E.J.; Bergmann, P.J. Tail autotomy, tail size, and locomotor performance in lizards. Physiol. Biochem. Zool. 2013, 86, 669679, doi:10.1086/673890.

21. Daniels, C.B. Running: an escape strategy enhanced by autotomy. Herpetologica 1983, 39, 162-165.

22. Vitt, L.J.; Congdon, J.D.; Dickson, N.A. Adaptive strategies and energetics of tail autotomy in lizards. Ecology 1977, 58, $326-337$.

23. Colli, G.R.; Bastos, R.P.; Araujo, A.F.B. The character and dynamics of the Cerrado herpetofauna. In The Cerrados of Brazil: Ecology and Natural History of a Neotropical Savannah, Oliveira, P.S., Marquis, R.J., Eds.; Columbia University Press: New York, 2002; Volume 1, pp. 223-241.

24. Santos, M.G.; Nogueira, C.; Giugliano, L.G.; Colli, G.R. Landscape evolution and phylogeography of Micrablepharus atticolus (Squamata, Gymnophthalmidae), an endemic lizard of the Brazilian Cerrado. J Biogeogr 2014, 41, 1506-1519, doi:10.1111/jbi.12291.

25. Gainsbury, A.M.; Colli, G.R. Lizard assemblages from natural Cerrado enclaves in southwestern Amazonia: The role of stochastic extinctions and isolation. Biotropica 2003, 35, 503-519, doi:10.1111/j.1744-7429.2003.tb00607.x.

26. Vieira, G.H.C.; Mesquita, D.O.; Péres Jr, A.K.; Kitayama, K.; Colli, G.R. Micrablepharus atticolus (NCN). Natural history. Herpetol Rev 2000, 31, 241-242.

27. Vitt, L.J. An introduction to the ecology of Cerrado lizards. J Herpetol 1991, 25, 79-90.

28. Vitt, L.J.; Caldwell, J.P. Ecological observations on Cerrado lizards in Rondônia, Brazil. J Herpetol 1993, $27,46-52$.

29. Sousa, H.C.; Soares, A.H.B.; Costa, B.M.; Pantoja, D.L.; Caetano, G.H.; Queiroz, T.A.; Colli, G.R. Fire regimes and the demography of the lizard Micrablepharus atticolus (Squamata, Gymnophthalmidae) in a biodiversity hotspot. South Am J Herpetol 2015, 10, 143-156.

30. Roscito, J.G.; Nunes, P.M.S.; Rodrigues, M.T. Digit evolution in gymnophthalmid lizards. Int. J. Dev. Biol. 2014, 58, 895-908, doi:10.1387/ijdb.140255jg.

31. Grizante, M.B.; Brandt, R.; Kohlsdorf, T. Evolution of body elongation in gymnophthalmid lizards: Relationships with climate. PLoS One 2012, 7, 7, doi:10.1371/journal.pone.0049772.

32. Renous, S.; Hofling, E.; Gasc, J.P. Respective role of the axial and appendicular systems in relation to the transition to limblessness. Acta Biotheor 1998, 46, 141-156, doi:10.1023/A:1001129920394.

33. Renous, S.; Hofling, E.; Gasc, J.P. On the rhythmical coupling of the axial and appendicular systems in small terrestrial lizards (Sauria: Gymnophthalmidae). Zool-Anal Complex Sy 1999, 102, 31-49.

34. Höfling, E.; Renous, S. High frequency of pauses during intermittent locomotion of small South American gymnophthalmid lizards (Squamata, Gymnophthalmidae). Phyllomedusa 2004, 3, 83-94.

35. Sousa, H.C.; Costa, B.M.; Morais, C.J.S.; Pantoja, D.L.; de Queiroz, T.A.; Vieira, C.R.; Colli, G.R. Blue tales of a blue-tailed lizard: Ecological correlates of tail autotomy in Micrablepharus atticolus (Squamata, Gymnophthalmidae) in a Neotropical savannah. J. Zool. (Lond.) 2016, 299, 202-212, doi:10.1111/jzo.12335.

36. Gillis, G.; Higham, T.E. Consequences of lost endings: caudal autotomy as a lens for focusing attention on tail function during locomotion. J Exp Biol 2016, 219, 2416-2422, doi:10.1242/jeb.124024.

37. Christian, K.A.; Tracy, C.R. The effect of the thermal environment on the ability of hatchling Galapagos land iguanas to avoid predation during dispersal. Oecologia 1981, 49, 218-223, doi:10.1007/bf00349191.

38. Jayne, B.C.; Bennett, A.F. Selection on locomotor performance capacity in a natural population of garter snakes. Evolution 1990, 44, 1204-1229, doi:10.1111/j.1558-5646.1990.tb05226.x.

39. Greenwald, O.E. Thermal dependence of striking and prey capture by gopher snakes. Copeia 1974, 1974, 141-148, doi:10.2307/1443016.

40. Webb, W.P. Body form, locomotion and foraging in aquatic vertebrates. American Zoologist 1984, 24, 107-120, doi:10.1093/icb/24.1.107.

41. Garland, T.; Hankins, E.; Huey, R.B. Locomotor capacity and social dominance in male lizards. Funct Ecol 1990, 4, 243-250, doi:10.2307/2389343.

42. Chapple, D.G.; Swain, R. Effect of caudal autotomy on locomotor performance in a viviparous skink, Niveoscincus metallicus. Funct Ecol 2002, 16, 817-825, doi:10.1046/j.1365-2435.2002.00687.x.

43. Dayananda, B.; Ibarguengoytia, N.; Whiting, M.J.; Webb, J.K. Effects of pregnancy on body temperature and locomotor performance of velvet geckos. J Therm Biol 2017, 65, 64-68, doi:10.1016/j.jtherbio.2017.02.005.

44. Garland, J.T. The relation between maximal running speed and body mass in terrestrial mammals. J. Zool. (Lond.) 1983, 199, 157170.

45. Pironon, S.; Papuga, G.; Villellas, J.; Angert, A.L.; Garcia, M.B.; Thompson, J.D. Geographic variation in genetic and demographic performance: New insights from an old biogeographical paradigm. Biol Rev Camb Philos Soc 2017, 92, 1877-1909, doi:10.1111/brv.12313.

46. Lin, Z.H.; Ji, X. Partial tail loss has no severe effects on energy stores and locomotor performance in a lacertid lizard, Takydromus septentrionalis. J. Comp. Physiol. B-Biochem. Syst. Environ. Physiol. 2005, 175, 567-573, doi:10.1007/s00360-005-0017-z.

47. Alvares, C.A.; Stape, J.L.; Sentelhas, P.C.; Goncalves, J.L.D.; Sparovek, G. Köppen's climate classification map for Brazil. Meteorol Z 2013, 22, 711-728, doi:10.1127/0941-2948/2013/0507. 
48. Angilletta, J.M.J. Thermal Adaptation: A Theoretical and Empirical Synthesis. Thermal Adaptation: A Theoretical and Empirical Synthesis 2009, 1-302, doi:10.1093/acprof:oso/9780198570875.001.1.

49. Wood, S.N. Generalized Additive Models: An Introduction with R, 2nd ed.; CRC Press, Taylor \& Francis Group: Boca Raton, FL, 2017; p. 476.

50. Wood, S.N. Fast stable restricted maximum likelihood and marginal likelihood estimation of semiparametric generalized linear models. J. R. Stat. Soc. Ser. B-Stat. Methodol. 2011, 73, 3-36, doi:10.1111/j.1467-9868.2010.00749.x.

51. R Core Team R: A Language and Environment for Statistical Computing, R Foundation for Statistical Computing: Vienna, Austria, 2018.

52. Wood, S., N. . Generalized Additive Models: An Introduction With R; 2006; Volume 16, p. 391.

53. Bartón, K. MuMIn: Multi-Model Inference, R package version 1.40.4; 2018.

54. Leeb, H.; Potscher, B.M. Model selection and inference: Facts and fiction. Economet. Theory 2005, 21, 21-59, doi:10.1017/s0266466605050036.

55. Hjort, N.L.; Claeskens, G. Frequentist model average estimators. J. Am. Stat. Assoc. 2003, 98, 879-899, doi:10.1198/016214503000000828.

56. Burnham, K.P.; Anderson, D.R. Model Selection and Multi-Model Inference, 2nd ed.; Springer-Verlag: New York, $2002 ;$ p. 496.

57. Liang, H.; Zou, G.H.; Wan, A.T.K.; Zhang, X.Y. Optimal weight choice for frequentist model average estimators. J. Am. Stat. Assoc. 2011, 106, 1053-1066, doi:10.1198/jasa.2011.tm09478.

58. Galipaud, M.; Gillingham, M.A.F.; David, M.; Dechaume-Moncharmont, F.X. Ecologists overestimate the importance of predictor variables in model averaging: A plea for cautious interpretations. Methods in Ecology and Evolution 2014, 5, 983-991, doi:Doi 10.1111/2041-210x.12251.

59. Galipaud, M.; Gillingham, M.A.F.; Dechaume-Moncharmont, F.X. A farewell to the sum of Akaike weights: The benefits of alternative metrics for variable importance estimations in model selection. Methods in Ecology and Evolution 2017, 8, 1668-1678, doi:10.1111/2041-210x.12835.

60. Lukacs, P.M.; Burnham, K.P.; Anderson, D.R. Model selection bias and Freedman's paradox. Ann. Inst. Stat. Math. 2010, 62, 117125, doi:10.1007/s10463-009-0234-4.

61. Bauwens, D.; Garland, T.; Castilla, A.M.; Vandamme, R. Evolution of sprint speed in lacertid lizards: Morphological, physiological, and behavioral covariation. Evolution 1995, 49, 848-863.

62. Sinclair, B.J.; Marshall, K.E.; Sewell, M.A.; Levesque, D.L.; Willett, C.S.; Slotsbo, S.; Dong, Y.W.; Harley, C.D.G.; Marshall, D.J.; Helmuth, B.S.; et al. Can we predict ectotherm responses to climate change using thermal performance curves and body temperatures? Ecol. Lett. 2016, 19, 1372-1385, doi:10.1111/ele.12686.

63. Angilletta, M.J.; Bennett, A.F.; Guderley, H.; Navas, C.A.; Seebacher, F.; Wilson, R.S. Coadaptation: A unifying principle in evolutionary thermal biology. Physiological and Biochemical Zoology 2006, 79, 282-294, doi:10.1086/499990.

64. Higham, T.E.; Russell, A.P.; Zani, P.A. Integrative biology of tail autotomy in lizards. Physiol. Biochem. Zool. 2013, 86, 603-610, doi: $10.1086 / 673875$.

65. Huey, R.B.; Stevenson, R.D. Integrating thermal physiology and ecology of ectotherms: A discussion of approaches. American Zoologist 1979, 19, 357-366.

66. Huey, R.B. Temperature, physiology, and the ecology of reptiles. In Biology of the Reptilia, Gans, C., Pough, F.H., Eds.; Academic Press: London, 1982; Volume 12, pp. 25-91.

67. Angilletta, M.J., Jr.; Niewiarowski, P.H.; Navas, C.A. The evolution of thermal physiology in ectotherms. J Therm Biol 2002, 27, 249-268, doi:10.1016/s0306-4565(01)00094-8.

68. Strangas, M.L.; Navas, C.A.; Rodrigues, M.T.; Carnaval, A.C. Thermophysiology, microclimates, and species distributions of lizards in the mountains of the Brazilian Atlantic Forest. Ecography 2019, 42, 354-364, doi:10.1111/ecog.03330.

69. Colli, G.R.; Hoogmoed, M.S.; Cannatella, D.C.; Cassimiro, J.; Gomes, J.O.; Ghellere, J.M.; Nunes, P.M.S.; Pellegrino, K.C.M.; Salerno, P.; De Souza, S.M.; et al. Description and phylogenetic relationships of a new genus and two new species of lizards from Brazilian Amazonia, with nomenclatural comments on the taxonomy of Gymnophthalmidae (Reptilia: Squamata). Zootaxa 2015, 4000, 401-427.

70. Clusella-Trullas, S.; Chown, S.L. Lizard thermal trait variation at multiple scales: a review. J. Comp. Physiol. B-Biochem. Syst. Environ. Physiol. 2014, 184, 5-21, doi:DOI 10.1007/s00360-013-0776-x.

71. Huey, R.B.; Kingsolver, J.G. Evolution of thermal sensitivity of ectotherm performance. Tree 1989, 4, 131-135.

72. Van Damme, R.; Vanhooydonck, B. Origins of interspecific variation in lizard sprint capacity. Funct Ecol 2001, 15, 186-202, doi:10.1046/j.1365-2435.2001.00513.x.

73. Pontes-da-Silva, E.; Magnusson, W.E.; Sinervo, B.; Caetano, G.H.; Miles, D.B.; Colli, G.R.; Diele-Viegas, L.M.; Fenker, J.; Santos, J.C.; Werneck, F.P. Extinction risks forced by climatic change and intraspecific variation in the thermal physiology of a tropical lizard. J Therm Biol 2018, 73, 50-60, doi:10.1016/j.jtherbio.2018.01.013.

74. Mendez-Galeano, M.A.; Paternina-Cruz, R.F.; Calderon-Espinosa, M.L. The highest kingdom of Anolis: Thermal biology of the Andean lizard Anolis heterodermus (Squamata: Dactyloidae) over an elevational gradient in the Eastern Cordillera of Colombia. J Therm Biol 2020, 89, 10, doi:10.1016/j.jtherbio.2019.102498.

75. Marques, E.Q.; Marimon, B.; Marimon, B.S.; Matricardi, E.A.T.; Mews, H.A.; Colli, G.R. Redefining the Cerrado-Amazonia transition: Implications for conservation. Biodivers. Conserv. 2020, 29, 1501-1517, doi:10.1007/s10531-019-01720-z. 
76. Gaston, K.J. Geographic range limits: Achieving synthesis. Proc. R. Soc. B-Biol. Sci. 2009, 276, 1395-1406, doi:10.1098/rspb.2008.1480.

77. Garner, T.W.J.; Pearman, P.B.; Angelone, S. Genetic diversity across a vertebrate species' range: a test of the central-peripheral hypothesis. Mol. Ecol. 2004, 13, 1047-1053, doi:10.1111/j.1365-294X.2004.02119.x.

78. Pironon, S.; Villellas, J.; Morris, W.F.; Doak, D.F.; Garcia, M.B. Do geographic, climatic or historical ranges differentiate the performance of central versus peripheral populations? Glob. Ecol. Biogeogr. 2015, 24, 611-620, doi:10.1111/geb.12263.

79. Valladares, F.; Matesanz, S.; Guilhaumon, F.; Araujo, M.B.; Balaguer, L.; Benito-Garzon, M.; Cornwell, W.; Gianoli, E.; van Kleunen, M.; Naya, D.E.; et al. The effects of phenotypic plasticity and local adaptation on forecasts of species range shifts under climate change. Ecol. Lett. 2014, 17, 1351-1364, doi:10.1111/ele.12348.

80. Shine, R. Effects of pregnancy on locomotor performance: an experimental study on lizards. Oecologia 2003, 136, 450-456, doi:10.1007/s00442-003-1281-9.

81. Olsson; Shine; Bak, O. Locomotor impairment of gravid lizards: is the burden physical or physiological? Journal of Evolutionary Biology 2001, 13, 263-268, doi:10.1046/j.1420-9101.2000.00162.x.

82. Bauwens, D.; Thoen, C. Escape tactics and vulnerability to predation associated with reproduction in the lizard Lacerta vivipara; 1981; Volume 50, pp. 733-743.

83. Itonaga, K.; Jones, S.M.; Wapstra, E. Do gravid females become selfish? Female allocation of energy during gestation. Physiological and Biochemical Zoology 2012, 85, 231-242, doi:10.1086/665567.

84. Sinervo, B.; Hedges, R.; Adolph, S.C. Decreased sprint speed as a cost of reproduction in the lizard Sceloporus Occidentalis: Variation among populations. J Exp Biol 1991, 155, 323-336.

85. Seigel, R.A.; Huggins, M.M.; Ford, N.B. Reduction in locomotor ability as a cost of reproduction in gravid snakes. Oecologia 1987, 73, 481-485, doi:10.1007/bf00379404.

86. Shine, R. “Costs" of reproduction in reptiles. Oecologia 1980, 46, 92-100, doi:10.1007/BF00346972.

87. Van Damme, R.; Bauwens, D.; F. Verheyen, R. Effect of relative clutch mass on sprint speed in the lizard Lacerta vivipara. J Herpetol 1989, 23, 459 - 461, doi:10.2307/1564069.

88. Cooper Jr, W.E.; Wilson, D.S.; Smith, G.R. Sex, reproductive status, and cost of tail autotomy via decreased running speed in lizards. Ethol 2009, 115, 7-13, doi:10.1111/j.1439-0310.2008.01575.x.

89. Shine, R. Locomotor speeds of gravid lizards: Placing 'costs of reproduction' within an ecological context. Functional Ecology 2003, 17, 526-533, doi:10.1046/j.1365-2435.2003.00756.x.

90. Clemente, C.J.; Withers, P.C.; Thompson, G. Optimal body size with respect to maximal speed for the yellow-spotted monitor lizard (Varanus panoptes; Varanidae). Physiol. Biochem. Zool. 2012, 85, 265-273, doi:10.1086/665275.

91. Jones, J.H.; Lindstedt, S.L. Limits to maximal performance. Annual review of physiology 1993, 55, 547-569, doi:10.1146/annurev.ph.55.030193.002555.

92. Heglund, N.C.; Taylor, C.R.; McMahon, T.A. Scaling stride frequency and gait to animal size: mice to horses. Science (New York, N.Y.) 1974, 186, 1112-1113.

93. Schmidt-Nielsen, K. Locomotion: Energy cost of swimming, flying, and running. Science (New York, N.Y.) 1972, $177,222$.

94. Zamora-Camacho, F.J.; Reguera, S.; Moreno-Rueda, G. Does tail autotomy affect thermoregulation in an accurately thermoregulating lizard? Lessons from a 2200-m elevational gradient. J. Zool. (Lond.) 2015, 297, 204-210, doi:10.1111/jzo.12266.

95. Downes, S.J.; Shine, R. Why does tail loss increase a lizard's later vulnerability to snake predators? Ecology 2001, 82, $1293-1303$.

96. Jagnandan, K.; Russell, A.P.; Higham, T.E. Tail autotomy and subsequent regeneration alter the mechanics of locomotion in lizards. J Exp Biol 2014, 217, 3891-3897, doi:10.1242/jeb.110916.

97. Hamley, T. Functions of the tail in bipedal locomotion of lizards dinosaurs and pterosaurs. Memoirs of the Queensland Museum 1990, 28, 153-158.

98. Höfling, E.; Renous, S.; Curcio, F.F.; Eterovic, A.; Santos Filho, P.S.S. Effects of surface roughness on the locomotion of a longtailed lizard, Colobodactylus taunayi Amaral, 1933 (Gymnophthalmidae: Heterodactylini). International Journal of Zoology 2012, 2012 Article ID 627470, 1-16.

99. Vitt, L.J.; Caldwell, J.P. Herpetology. An Introductory Biology of Amphibians and Reptiles, 4th ed.; Elsevier, Inc.: London, 2014.

100. Gans, C. Tetrapod limblessness: Evolution and functional corollaries. American Zoologist 1975, 15, 455-467.

101. da Silva, F.O.; Fabre, A.C.; Savriama, Y.; Ollonen, J.; Mahlow, K.; Herrel, A.; Muller, J.; Di-Poi, N. The ecological origins of snakes as revealed by skull evolution. Nat. Commun. 2018, 9, 11, doi:10.1038/s41467-017-02788-3.

102. McElroy, E.J. The effect of tail autotomy on locomotor performance in the long tailed grass lizard, Takydromus sexlineatus. Integr. Comp. Biol. 2011, 51, E89-E89.

103. Wiens, J.J.; Slingluff, J.L. How lizards turn into snakes: A phylogenetic analysis of body-form evolution in anguid lizards. Evolution 2001, 55, 2303-2318.

104. Wiens, J.J.; Brandley, M.C.; Reeder, T.W. Why does a trait evolve multiple times within a clade? Repeated evolution of snakelike body form in squamate reptiles. Evolution 2006, 60, 123-141. 